\title{
Perdas do nitrogênio da uréia no sistema solo-planta em dois ciclos de cana-de-açúcar ${ }^{(1)}$
}

\author{
Paulo Cesar Ocheuze Trivelin ${ }^{(2)}$, Mauro Wagner de Oliveira(3), André Cesar Vitti(4), \\ Glauber José de Castro Gava( ${ }^{(4)}$ e José Albertino Bendassolli(2)
}

\begin{abstract}
Resumo - O objetivo deste trabalho foi quantificar as perdas de $\mathrm{N}$ do sistema solo-cana-de-açúcar, nos ciclos de cana-planta e de cana-soca. Desenvolveram-se dois experimentos em vasos de $220 \mathrm{~L}$, contendo solo de classe textural arenosa. Os fatores de estudo do experimento com cana-planta foram dois tipos de restos culturais incorporados ao solo e quatro doses de $\mathrm{N}$ no plantio. No experimento com cana-soca, estudaram-se duas formas de aplicação da uréia em superfície: sobre a palha ou sobre o solo descoberto, ou na profundidade de $15 \mathrm{~cm}$, e duas fontes de $\mathrm{K}$ : $\mathrm{KCl}$ ou vinhaça. Utilizou-se uréia marcada $\operatorname{com}^{15} \mathrm{~N}$. O delineamento experimental foi o de blocos ao acaso, com três repetições. Em cana-planta, as perdas foram de $12 \%$ do $\mathrm{N}$-uréia (recuperação de $88 \%$ ), que ocorreram, principalmente, por desnitrificação no solo. Em cana-soca, a aplicação da uréia em profundidade resultou em $81 \%$ de recuperação do $\mathrm{N}$-fertilizante, enquanto na superficial, somente em $50 \%$. Perdas de $50 \%$ do N-uréia aplicado em superfície representam aquelas que ocorreram no solo, principalmente, por volatilização de amônia, e, também, pela parte aérea da cana-de-açúcar. Com aplicação em profundidade, as perdas foram de $19 \%$ e se deram pela parte aérea das plantas para a atmosfera, sendo a perda total de $\mathrm{N}$ (da uréia e de outras fontes) assimilado pela cultura da ordem de $90 \mathrm{~kg} \mathrm{ha}^{-1}$.
\end{abstract}

Termos para indexação: desnitrificação, perdas de nitrogênio pelas folhas, balanço de ${ }^{15} \mathrm{~N}$

Nitrogen losses of applied urea in the soil-plant system during two sugar cane cycles

Abstract - The objective of this work was to quantify the losses of $\mathrm{N}$ from the soil-plant system, in the cane plant and sugar cane ratoon-cycle. Two experiments were carried out in 220 L-pots filled with sandy soil. In the experiment with cane plant two factors were studied: two types of sugar cane crop residues incorporated in the soil and four doses of $\mathrm{N}$ applied as urea. In the experiment with sugar cane ratoon two forms of urea application on soil surface were studied: over the straw (trash) or uncovered soil, or at a depth of $15 \mathrm{~cm}$, and two potassium sources: $\mathrm{KCl}$ or vinasse. Urea labeled with ${ }^{15} \mathrm{~N}$ was used in both experiments. The experimental design was randomized blocks, with three replications. In the cane plant experiment, $12 \%$ of the $\mathrm{N}$-urea applied was lost (recovery of $88 \%$ ), due to denitrification. In the experiment with sugar cane ratoon, when urea was applied in the soil at $15 \mathrm{~cm}$ depth, recovery of the $\mathrm{N}$-fertilizer was $81 \%$, while $50 \%$ was recovered when urea was applied on the surface. Losses of $50 \%$ of the $\mathrm{N}$-urea applied to soil surface were due to ammonia volatilization in the soil, and also to ammonia volatilization through the sugar cane foliage. When urea was applied at $15 \mathrm{~cm}$ depth, $19 \%$ of the N-urea was lost from plant tops to the atmosphere, being the total loss of $\mathrm{N}$ (from urea and other sources assimilated by sugar cane) equivalent to $90 \mathrm{~kg} \mathrm{ha}^{-1}$.

Index terms: denitrification, nitrogen loss by foliage, ${ }^{15} \mathrm{~N}$ balance.

(1) Aceito para publicação em 5 de abril de 2001 .

(2) Universidade de São Paulo (USP), Centro de Energia Nuclear na Agricultura (Cena), Caixa Postal 96, CEP 13400-970 Piracicaba, SP. Bolsista do CNPq E-mail: pcotrive@cena.usp.br, jab@cena.usp.br

(3) Universidade Federal de Viçosa, Centro de Pesquisa e Melhoramento de Cana-de-Açúcar, Caixa Postal 342, CEP 35430-970 Ponte Nova, MG. E-mail: mwagner@mail.ufv.br

(4) USP, Cena. Bolsista da Fapesp. E-mail: acvitti@cena.usp.br, ggava@cena.usp.br

\section{Introdução}

$\mathrm{O} \mathrm{N}$ assimilado pelos vegetais pode, em parte, perder-se tanto pelas raízes, por exsudação, como pela parte aérea, por volatilização, principalmente na forma de amônia, por lixiviação de compostos solúveis na água das chuvas, ou mesmo por gutação, o que acarreta subestimativas nas determinações da sua utilização de fertilizantes $\left({ }^{15} \mathrm{~N}\right)$, feitas na maturidade. 
Durante a senescência foliar o aumento da hidrólise de proteínas é acompanhado pela redução nas atividades das enzimas glutamina sintetase (GS) e glutamato sintase (GOGAT), principais responsáveis pela assimilação da amônia no metabolismo do $\mathrm{N}$ nas plantas superiores. A redução na atividade dessas enzimas resulta em perdas de $\mathrm{NH}_{3}$ na corrente transpiratória. Essas perdas dependem do equilíbrio, em solução, entre a forma gasosa $\mathrm{NH}_{3}$ e a iônica $\mathrm{NH}_{4}{ }^{+}$, que é influenciado pela temperatura e pelo $\mathrm{pH}$ do meio (Holtan-Hartwig \& Bockman, 1994).

Holtan-Hartwig \& Bockman (1994) estimaram para culturas anuais, em clima temperado, perdas pela folhagem dos vegetais de 2 a $6 \mathrm{~kg} \mathrm{ha}^{-1} \mathrm{ano}^{-1}$ de $\mathrm{N}-\mathrm{NH}_{3}$. O estresse dos vegetais por doenças, déficit hídrico ou excesso de $\mathrm{N}$ pode aumentar as perdas de amônia. Por sua vez, a amônia da atmosfera pode ser absorvida pelos vegetais, após sua dissolução no filme de água que recobre a epiderme foliar e as cavidades estomáticas, principalmente com a formação do orvalho. A intensidade e o sentido com que ocorrem as trocas de amônia entre as folhas e a atmosfera dependem do ponto de compensação de amônia (Farquhar et al., 1980), que pode variar com a temperatura, intensidade luminosa e fotoperíodo; com a nutrição nitrogenada da planta, a espécie e a cultivar da mesma espécie, e o estádio vegetativo da planta (Holtan-Hartwig \& Bockman, 1994; Husted et al., 1996; Mattsson \& Schjoerring, 1996; Mattsson et al., 1997; Schjoerring et al., 1998). Nas concentrações de $\mathrm{NH}_{3}$ na atmosfera abaixo do ponto de compensação de amônia da planta, ocorre sua emissão pelas folhas; em concentrações acima, sua absorção (Farquhar et al., 1980; Holtan-Hartwig \& Bockman, 1994).

As concentrações de $\mathrm{NH}_{3}$ na atmosfera variam de $0,06 \mu \mathrm{g} \mathrm{m}^{-3}$, nos oceanos, até $300 \mu \mathrm{g} \mathrm{m}^{-3} \mathrm{em}$ locais livres de vento, onde existem fontes de emissão do gás; em áreas rurais está normalmente na faixa de 1 a $14 \mu \mathrm{g} \mathrm{m}^{-3}$ (Schlesinger \& Hartley, 1992; HoltanHartwig \& Bockman, 1994).

Em trabalhos realizados sobre balanços de amônia na Terra (Schlesinger \& Hartley, 1992; Duxbury, 1994; Weier, 1998), não foram mencionados os vegetais como fonte de $\mathrm{NH}_{3}$ à atmosfera. Em recente inventário global da amônia no planeta, Bouwman et al. (1997) incluíram as culturas agrícolas entre as principais fontes de $\mathrm{NH}_{3}$ para a atmosfe- ra, contribuindo com 3,6 Tg ano ${ }^{-1}$ de um total de $54 \mathrm{Tg} \mathrm{ano}^{-1} \mathrm{de} \mathrm{N}-\mathrm{NH}_{3}$. As principais fontes de amônia em agrossistemas são a queima da biomassa e de combustíveis fósseis, da aplicação de fertilizantes amídico-amoniacais, da decomposição de resíduos culturais, de dejetos de animais domésticos, além da emissão pela folhagem das culturas. Segundo Lobert et al. (1990), a amônia emitida pela queima de biomassa não é maior que $4 \%$ do conteúdo total de $\mathrm{N}$

No Estado de São Paulo, na cultura da cana-deaçúcar, efetua-se a aplicação de fertilizantes nitrogenados em profundidade $(15-25 \mathrm{~cm})$, sendo desprezíveis as perdas de $\mathrm{NH}_{3}$ (Lara Cabezas et al., 1987; Trivelin et al., 1994). Os dejetos de animais constituem-se em importante fonte de amônia em regiões com pecuária (Schlesinger \& Hartley, 1992; Bouwman et al., 1997).

O objetivo deste trabalho foi quantificar as perdas de $\mathrm{N}$ do sistema solo-planta, no ciclo de canaplanta e de cana-soca.

\section{Material e Métodos}

Os estudos foram desenvolvidos no campo experimental do posto meteorológico do Departamento de Ciências Exatas da Esalq/USP, em Piracicaba, SP. O experimento com cana-planta se estendeu de janeiro a dezembro de 1996. O volume total de água recebido pela cultura, de precipitações e de irrigações, nas épocas de estiagem, foi de $2.014 \mathrm{~mm}$ (1.255 e $759 \mathrm{~mm}$, respectivamente, chuvas e irrigação), e as médias das temperaturas máximas e mínimas foram de 28,7 e $15,8^{\circ} \mathrm{C}$, respectivamente. No decorrer do segundo experimento, de janeiro a novembro de 1997, as médias das temperaturas máximas e mínimas foram de 28,4 e $15,5^{\circ} \mathrm{C}$, respectivamente. A cultura recebeu uma lâmina de água de $1.839 \mathrm{~mm}$, sendo $923 \mathrm{~mm}$ de precipitações e $916 \mathrm{~mm}$ de irrigações

O experimento constou de 48 parcelas constituídas por vasos de $220 \mathrm{~L}$ ( $60 \mathrm{~cm}$ de diâmetro e $90 \mathrm{~cm}$ de altura) contendo terra de textura arenosa $\left(840,60\right.$ e $100 \mathrm{~g} \mathrm{~kg}^{-1}$, respectivamente, de areia total, silte e argila) com as características químicas: $\mathrm{pH}, 4,4\left(\mathrm{CaCl}_{2}\right) ; 19 \mathrm{~g} \mathrm{~kg}^{-1} \mathrm{de} \mathrm{MO} ; 10 \mathrm{mg} \mathrm{dm}{ }^{-3}$ de $\mathrm{P}$ (resina); K, Ca, Mg e H+Al: 1, 17, 3 e 34 mmol $_{\mathrm{c}} \mathrm{dm}^{-3}$, respectivamente. Os vasos possuíam, na parte inferior, um dreno constituído de uma camada de $10 \mathrm{~cm}$ de brita zero, coberta por manta Bidim, e foram mantidos ao ar livre. 
O experimento com cana-planta (24 vasos), instalado em janeiro de 1996, constou de dois tipos de restos culturais incorporados ao solo, simulando a reforma de canavial após a colheita mecânica da cana-de-açúcar, com queima (CQ) ou sem prévia despalha a fogo (SQ); e de quatro doses de N no plantio: 0, 30, 60 e $90 \mathrm{~kg} \mathrm{ha}^{-1}$. No SQ, os restos culturais - folhas secas (177 g por vaso de matéria seca (MS); 386 e 3,99 $\mathrm{g} \mathrm{kg}^{-1}$, de $\mathrm{C}$ e $\mathrm{N}$, respectivamente), colmos aéreos e ponteiros (122 g por vaso de MS; $423 \mathrm{e}$ $7,84 \mathrm{~g} \mathrm{~kg}^{-1}$ de $\mathrm{C}$ e $\mathrm{N}$, respectivamente), e rizomas (251 g por vaso de MS; 400 e $5,70 \mathrm{~g} \mathrm{~kg}^{-1}$ de $\mathrm{C}$ e $\mathrm{N}$, respectivamente) - foram misturados à terra dos vasos $(0-25 \mathrm{~cm}$ de profundidade) em quantidades equivalentes a $6,3,4,3$ e $8,9 \mathrm{Mg} \mathrm{ha}^{-1}$ de matéria seca (MS total equivalente a $\left.19,5 \mathrm{Mg} \mathrm{ha}^{-1}\right)$, respectivamente, referidas com base em superfície e considerada a área dos vasos como sendo $0,283 \mathrm{~m}^{2}$. Esses valores foram definidos tomando por base as produções médias de resíduos culturais obtidas por Camargo (1989), Abramo Filho et al. (1993) e Trivelin et al. (1995). No CQ os restos culturais foram misturados ao solo nas mesmas quantidades acima especificadas, excluindo-se as folhas secas, procurando-se, assim, simular uma condição de reforma do canavial com despalha a fogo antes da colheita mecanizada; a quantidade equivalente de restos culturais foi de $13,2 \mathrm{Mg} \mathrm{ha}^{-1}$. Todos os restos culturais foram grosseiramente triturados antes de misturados ao solo. O experimento com cana-soca (24 vasos) constou da implantação, em janeiro de 1996, também dos tratamentos SQ e CQ.

$\mathrm{Na}$ camada superficial da terra de todos os 48 vasos (0-25 cm de profundidade e correspondente a $90 \mathrm{~kg}$ de terra), adicionaram-se os restos culturais, conforme o tratamento, e $\mathrm{CaO}$ e $\mathrm{MgO}$, numa relação 2:1 (m/m), em quantidade suficiente para elevar a $60 \%$ a saturação por bases Dez dias após a adição do corretivo e dos restos culturais ao solo, realizou-se a adubação de plantio. Transplantaram-se três mudas de cana-de-açúcar da cultivar SP 80-1842, com, aproximadamente, $20 \mathrm{~cm}$ de altura, para cada vaso. A adubação de plantio foi realizada no fundo de cova com $15 \mathrm{~cm}$ de profundidade. $\mathrm{O} \mathrm{KCl} \mathrm{e} \mathrm{o} \mathrm{superfosfato}$ triplo foram aplicados em todas as parcelas, na dose equivalente a $120 \mathrm{~kg} \mathrm{ha}^{-1}$ dos respectivos óxidos. Nas parcelas do experimento com cana-planta aplicaram-se 0,899,2, $1.798,4$ e 2.697,6 mg de $\mathrm{N}$-uréia por vaso, com $10,10 \%$ de átomos de abundância de ${ }^{15} \mathrm{~N}$, equivalentes a $0,30,60$ e $90 \mathrm{~kg} \mathrm{ha}^{-1} \mathrm{de} \mathrm{N}$. As parcelas destinadas ao experimento com cana-soca receberam $899,2 \mathrm{mg}$ de $\mathrm{N}$ por vaso (uréia), equivalente à dose de $30 \mathrm{~kg} \mathrm{ha}^{-1} \mathrm{de} \mathrm{N}$.

O experimento com cana-planta ( 24 parcelas) foi colhido em dezembro de 1996. Na mesma época, fez-se o primeiro corte da parte aérea das plantas das parcelas com cana-soca, instalando-se os tratamentos desse experimen- to. Nas parcelas do tratamento $\mathrm{SQ}$, a superfície do solo foi coberta com palha de cana-de-açúcar, constituída por folhas secas e ponteiros grosseiramente triturados; no CQ, o solo ficou descoberto, aplicando-se na superfície as cinzas resultantes da queima de quantidade correspondente de palha do tratamento SQ. A massa de matéria seca de palha colocada por vaso foi, em média, de $592 \mathrm{~g}$, equivalente a $21 \mathrm{Mg} \mathrm{ha}^{-1}$

No experimento com cana-soca, estudaram-se duas formas de aplicação da uréia nos tratamentos SQ e CQ: em superfície, sobre a palhada ou sobre o solo descoberto, e na profundidade de $15 \mathrm{~cm}$, e duas fontes de potássio: $\mathrm{KCl}$ ou vinhaça. Utilizou-se solução de uréia $\left(78,4 \mathrm{~g} \mathrm{~L}^{-1}\right) \mathrm{com}$ $10,08 \%$ de átomos de ${ }^{15} \mathrm{~N}$. As quantidades de $\mathrm{N}$ e $\mathrm{K}_{2} \mathrm{O}$ aplicadas por vaso foram, respectivamente, de $2.643 \mathrm{e}$ $3.510 \mathrm{mg}$, e equivalentes a 90 e $120 \mathrm{~kg} \mathrm{ha}^{-1}$. Esse experimento foi colhido em novembro de 1997.

Tanto no experimento com a cana-planta (1996) como no de cana-soca (1997), foi sempre recolhida a solução percolada no solo, que atingia o dreno em cada vaso, sendo

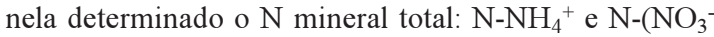
$+\mathrm{NO}_{2}{ }^{-}$), conforme Keeney \& Nelson (1982), e de abundância de ${ }^{15} \mathrm{~N}$, por espectrometria de massas (Trivelin et al., 1973).

Ao final de cada experimento efetuou-se a colheita das plantas, amostrando-se a parte aérea e a subterrânea, e do solo de todas as parcelas, após a retirada da parte subterrânea da cana-de-açúcar. No segundo experimento, também foi amostrada a palhada residual na superfície do solo. Procederam-se as determinações de N-total e de abundância de ${ }^{15} \mathrm{~N}$ em amostras de plantas, de solo e, também, da palhada residual no segundo experimento (Trivelin et al., 1973).

A recuperação porcentual do N-uréia $(\mathrm{R})$ foi determinada pela expressão:

$\mathrm{R}=(\mathrm{Nppf} / \mathrm{Naf}) .100$

sendo:

$\mathrm{Nppf}=[(\mathrm{A}-\mathrm{C}) /(\mathrm{B}-\mathrm{C})] . \mathrm{NT}$

onde: A e B abundância de ${ }^{15} \mathrm{~N}$ (\% de átomos) da planta e da uréia- ${ }^{15} \mathrm{~N}$, respectivamente; $\mathrm{C}$ a abundância natural de ${ }^{15} \mathrm{~N}(0,366 \%$ de átomos); NT é o conteúdo de nitrogênio da planta (grama por parcela) e Naf a quantidade de $\mathrm{N}$-uréia aplicada (miligrama por parcela).

O delineamento experimental foi o de blocos ao acaso, com três repetições, e os resultados de recuperação do $\mathrm{N}$-uréia foram submetidos à análise da variância (teste $\mathrm{F}$ a $95 \%$ de probabilidade), sendo o teste de Tukey $(\mathrm{p}=0,05)$ usado nas comparações de médias dos tratamentos.

\section{Resultados e Discussão}

Houve efeito de resíduos culturais na recuperação do $\mathrm{N}$ da uréia no solo no experimento com cana- 
planta, evidenciando no tratamento que simulou a reforma de canavial sem queima (SQ) a maior média (Tabela 1). Esse resultado indica haver uma relação direta entre a quantidade de resíduos culturais incorporados e o efeito residual do N-uréia no solo. Nas condições do experimento, não ocorreu na planta efeito dos fatores estudados na recuperação porcentual do N-fertilizante. Durante o período experimental, também não houve perdas mensuráveis de $\mathrm{N}$ derivado da uréia $\left({ }^{15} \mathrm{~N}\right)$ por lixiviação, na profundidade de $90 \mathrm{~cm}$. O N total lixiviado foi equivalente a $4,5 \mathrm{~kg} \mathrm{ha}^{-1}$ de $\mathrm{N}$ e oriundo do $\mathrm{N}$ mineralizado no solo (Oliveira et al., 1999).

Uma vez que foram tomados cuidados para evitar erros sistemáticos, as perdas se deram do sistema solo-planta para a atmosfera (Tabela 1). Essas perdas podem ter ocorrido, no todo ou em parte, por desnitrificação do $\mathrm{NO}_{3}$ derivado da uréia. No experimento existiram condições favoráveis à desnitrificação. A incorporação dos restos culturais ao solo e o consumo de oxigênio pelos microrganismos mineralizadores dessa matéria orgânica resultaram, muito provavelmente, em condição anóxica no solo, levando à reação de redução do $\mathrm{NO}_{3}$ pelos microrga- nismos desnitrificadores, quimiorganotróficos anaeróbios facultativos. Além disso, as chuvas ocorridas no início e no fim do experimento mantiveram o solo saturado com água, favorecendo a anaerobiose (Figura 1). Dobbie et al. (1999) encontraram perdas por desnitrificação em culturas como cana-de-açúcar fertilizada com $\mathrm{N}$ e irrigada, pastagem e florestas tropicais, variáveis de 0,3 a $18,4 \mathrm{~kg} \mathrm{ha}^{-1}$ de $\mathrm{N}-\mathrm{N}_{2} \mathrm{O}$, e verificaram que elas cresciam exponencialmente com o preenchimento do espaço poroso do solo pela água. Outra possibilidade que justificaria as perdas (Tabela 1) refere-se à volatilização de amônia pela parte aérea da cultura. Entre as duas, nesse caso, a desnitrificação parece ser a mais provável.

Em relação às trocas de amônia que normalmente ocorrem entre os vegetais e a atmosfera, é possível inferir que a cana-de-açúcar, no ciclo de cana-planta, considerando-se neste experimento a cultivar SP 80-1842, com características de precocidade (Quarta..., 1993), aliada às condições experimentais e fatores meteorológicos, em especial às hídricas, apresentou ponto de compensação para amônia inferior à concentração de $\mathrm{NH}_{3}$ da atmosfera, o que favoreceu a absorção, sem que houvesse emissão de amô-

Tabela 1. Recuperação do nitrogênio da uréia (\%) no sistema solo-planta no ciclo de cana-planta.

\begin{tabular}{|c|c|c|c|c|c|c|}
\hline \multirow[t]{2}{*}{ Restos culturais } & \multirow{2}{*}{$\begin{array}{l}\text { Dose de nitrogênio } \\
\quad\left(\mathrm{kg} \mathrm{ha}^{-1}\right)\end{array}$} & \multicolumn{5}{|c|}{ Recuperação do nitrogênio da uréia } \\
\hline & & Solo & Planta & Solo-planta & Lixiviação $^{(1)}$ & Perdas $^{(2)}$ \\
\hline \multirow[t]{3}{*}{ Sem queima (SQ) } & 30 & $42 \pm 4^{(3)}$ & $51 \pm 2$ & $93 \pm 4$ & $0 \pm 0$ & $7 \pm 4$ \\
\hline & 60 & $37 \pm 2$ & $51 \pm 5$ & $89 \pm 2$ & $0 \pm 0$ & $11 \pm 2$ \\
\hline & 90 & $34 \pm 3$ & $56 \pm 4$ & $90 \pm 3$ & $0 \pm 0$ & $10 \pm 3$ \\
\hline \multirow[t]{3}{*}{ Com queima (CQ) } & 30 & $32 \pm 4$ & $58 \pm 3$ & $90 \pm 7$ & $0 \pm 0$ & $10 \pm 7$ \\
\hline & 60 & $27 \pm 2$ & $56 \pm 5$ & $83 \pm 7$ & $0 \pm 0$ & $17 \pm 7$ \\
\hline & 90 & $31 \pm 1$ & $53 \pm 4$ & $85 \pm 4$ & $0 \pm 0$ & $15 \pm 4$ \\
\hline Média do fator $\mathrm{SQ}^{(4)}$ & & $38 \mathrm{a}$ & $53 a$ & $91 \mathrm{a}$ & & $9 \mathrm{a}$ \\
\hline Média do fator $\mathrm{CQ}^{(4)}$ & & $30 \mathrm{~b}$ & $56 \mathrm{a}$ & $86 \mathrm{a}$ & & $1 \mathrm{a}$ \\
\hline Média geral & & 34 & 54 & 88 & & $12 \pm 2^{(5)}$ \\
\hline Restos culturais (R) & & $8,5^{*}$ & $0,8^{\mathrm{ns}}$ & $1,1^{\mathrm{ns}}$ & & $1,1^{\mathrm{ns}}$ \\
\hline Dose de N (D) & & $1,2^{\mathrm{ns}}$ & $0,05^{\mathrm{ns}}$ & $0,6^{\mathrm{ns}}$ & & $0,6^{\mathrm{ns}}$ \\
\hline $\mathrm{R} \times \mathrm{D}$ & & $0,9^{\text {ns }}$ & $0,6^{\mathrm{ns}}$ & $0,03^{\mathrm{ns}}$ & & $0,03^{\mathrm{ns}}$ \\
\hline CV $(\%)$ & & 16 & 13 & 11 & & 81 \\
\hline
\end{tabular}

${ }^{(1)}$ Fonte: Oliveira et al. (1999). (2)Perdas $=100$ - (solo-planta). ${ }^{(3)}$ Média e desvio-padrão da média $\left(\mathrm{m} \pm \mathrm{s}_{\mathrm{m}}\right)$ para $\mathrm{n}=3$. (4)Médias seguidas de letras distintas diferem entre si pelo teste de Tukey a $5 \%$ de probabilidade. ${ }^{(5)}$ Média e desvio-padrão da média $\left(\mathrm{m} \pm \mathrm{s}_{\mathrm{m}}\right)$ para $\mathrm{n}=18$. ns Não-significativo. *Significativo a $5 \%$ de probabilidade, pelo teste $\mathrm{F}$ 
nia. Essa hipótese se apóia na significativa participação no conteúdo de $\mathrm{N}$ da cana-planta de outras fontes de $\mathrm{N}$ e no $\mathrm{N}$ absorvido da uréia que representou, em média, $11,5 \%$ do acumulado na planta toda $(7,0 \%, 11,7 \%$ e $15,9 \%$, respectivamente, para as doses de $\mathrm{N}$ equivalentes a 30,60 e $90 \mathrm{~kg} \mathrm{ha}^{-1}$ ) (Trivelin, 2000), e a melhor eficiência que a cana-planta apresenta comparativamente às soqueiras, em relação ao uso do $\mathrm{N}$, ou seja, quilograma de $\mathrm{N}$ utilizado por megagrama de colmos produzidos (Silva \& Casagrande, 1983). Ainda, nesse mesmo contexto, considerando as perdas verificadas neste e em trabalhos precedentes (Camargo, 1989; Trivelin et al., 1996), poder-se-á estender a hipótese formulada, in- ferindo-se que as rebrotas de cana-de-açúcar, dependendo das condições meteorológicas, apresentariam maior ponto de compensação para amônia, o que justificaria as perdas de $\mathrm{N}$ por volatilização pela folhagem da cultura.

No ciclo de cana-soca, somente o fator localização do fertilizante teve efeito na recuperação do $\mathrm{N}$ da uréia, no solo a uréia aplicada em superfície mostrou menor efeito residual do que a aplicada em profundidade (Tabela 2), provavelmente, em vista das maiores perdas de amônia por volatilização (Trivelin et al., 1994). Na palha, o maior efeito residual do N-uréia ocorreu nos tratamentos em que o fertilizante foi aplicado em superfície, indicando que
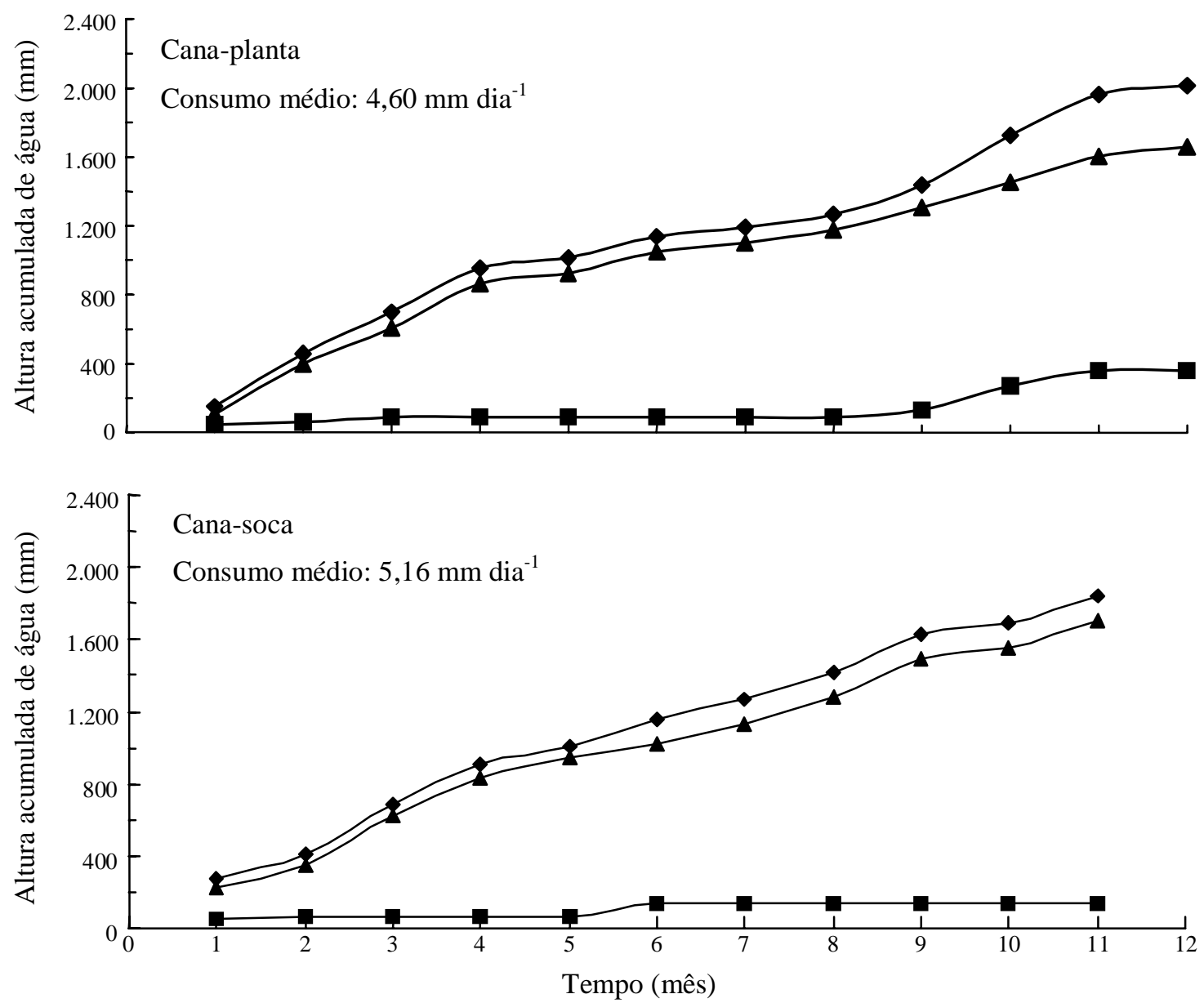

Figura 1. Balanço hídrico, representado pela precipitação mais a irrigação $(\neg-)$, a drenagem $(\neg-)$ e as perdas evapotranspirativas ( $\boldsymbol{-} \boldsymbol{-}$ ), no experimento com cana-planta (1996) e cana-soca (1997). 
houve imobilização do N-fertilizante pela biomassa microbiana, que se desenvolveu nesse material de alta relação C:N. Os resultados de imobilização do N da uréia aplicada em superfície foram superiores aos de Gava (1999), que obteve recuperação de $8 \pm 2 \%$. No presente trabalho, a uréia foi aplicada como solução concentrada sobre a palhada, após a aplicação da vinhaça, enquanto Gava (1999) aplicou mistura de vinhaça e uréia $\left(100 \mathrm{~m}^{3} \mathrm{ha}^{-1}\right.$ de vinhaça e $100 \mathrm{~kg} \mathrm{ha}^{-1}$ de N-uréia), o que pode ter facilitado a penetração da uréia no solo, reduzindo a imobilização pelos microrganismos na palhada. Por sua vez, a presença, na palha, do N da uréia aplicada em profundidade (Tabela 2) pode ser devido ao movimento ascendente, no solo, desse $\mathrm{N}$, que foi imobilizado pelos microrganismos, ou, o que é mais plausível, que as raízes da soca que se desenvolveram na superfície, logo abaixo da palhada, beneficiadas pelas condições microclimáticas da cobertura do solo, fizeram parte da amostra de palha, causando o enriquecimento em ${ }^{15} \mathrm{~N}$ desse material.

$\mathrm{Na}$ recuperação do $\mathrm{N}$-uréia na planta toda (parte aérea e sistema radicular da cana-soca), houve efeito da localização da uréia, da cobertura do solo e, também, de interações entre os fatores de estudo (Tabela 2). Com a aplicação do fertilizante em profundidade, no solo, a cana-soca recuperou, em média, $40 \%$ do N-uréia, representando mais do dobro do adubo aplicado em superfície. Esse resultado foi inferior à recuperação pela cana-planta (54\%) no primeiro experimento (Tabela 1), e equivalente à obtida por Trivelin et al. (1995), em relação à parte aérea de cana-soca de final de safra, em condições de campo, com uréia aplicada em profundidade. Na condição de solo coberto com palha (SQ), a recuperação do Nuréia na cana-soca foi inferior à sem palha (CQ).

Tabela 2. Recuperação do nitrogênio da uréia (\%) no sistema solo-planta no ciclo de cana-soca.

\begin{tabular}{|c|c|c|c|c|c|c|c|}
\hline \multirow{2}{*}{$\begin{array}{l}\text { Cobertura do } \\
\text { solo }\end{array}$} & \multirow{2}{*}{$\begin{array}{l}\text { Localização da } \\
\text { uréia }\end{array}$} & \multirow{2}{*}{$\begin{array}{l}\text { Fonte de } \\
\text { potássio }\end{array}$} & \multicolumn{5}{|c|}{ Recuperação do nitrogênio da uréia } \\
\hline & & & Solo & Palha & Planta & Solo-planta ${ }^{(1)}$ & Perdas $^{(2)}$ \\
\hline \multirow[t]{4}{*}{ Com palha (SQ) } & Superfície & Vinhaça & $25 \pm 1^{(3)}$ & $15 \pm 2$ & $8 \pm 1$ & $48 \pm 2$ & $52 \pm 2$ \\
\hline & Profundidade & Vinhaça & $39 \pm 3$ & $7 \pm 1$ & $38 \pm 5$ & $84 \pm 5$ & $16 \pm 5$ \\
\hline & Superfície & $\mathrm{KCl}$ & $28 \pm 7$ & $12 \pm 3$ & $9 \pm 2$ & $49 \pm 8$ & $51 \pm 8$ \\
\hline & Profundidade & $\mathrm{KCl}$ & $40 \pm 1$ & $9 \pm 1$ & $34 \pm 2$ & $83 \pm 3$ & $17 \pm 3$ \\
\hline \multirow[t]{4}{*}{ Sem palha (CQ) } & Superfície & Vinhaça & $25 \pm 1$ & - & $19 \pm 3$ & $44 \pm 3$ & $56 \pm 3$ \\
\hline & Profundidade & Vinhaça & $36 \pm 2$ & - & $44 \pm 2$ & $79 \pm 4$ & $21 \pm 4$ \\
\hline & Superfície & $\mathrm{KCl}$ & $27 \pm 2$ & - & $30 \pm 2$ & $57 \pm 1$ & $43 \pm 1$ \\
\hline & Profundidade & $\mathrm{KCl}$ & $35 \pm 2$ & - & $43 \pm 1$ & $78 \pm 1$ & $22 \pm 1$ \\
\hline \multicolumn{8}{|c|}{ Médias: cobertura do solo } \\
\hline \multirow{2}{*}{\multicolumn{3}{|c|}{$\begin{array}{l}\text { Com palha }(\mathrm{SQ})^{(4)} \\
\text { Sem palha }(\mathrm{CQ})^{(4)}\end{array}$}} & $33 \mathrm{a}$ & 11 & $22 b$ & $66 \mathrm{a}$ & $34 \mathrm{a}$ \\
\hline & & & $31 \mathrm{a}$ & - & $34 \mathrm{a}$ & $65 a$ & $35 \mathrm{a}$ \\
\hline \multicolumn{8}{|c|}{ Médias: localização da uréia } \\
\hline \multicolumn{3}{|c|}{ Superfície ${ }^{(4)}$} & $26 b$ & $14 \mathrm{a}$ & $17 \mathrm{~b}$ & $50 \mathrm{~b}$ & $50 \mathrm{a}$ \\
\hline \multicolumn{3}{|l|}{ Profundidade $^{(4)}$} & $37 \mathrm{a}$ & $8 \mathrm{~b}$ & $40 \mathrm{a}$ & $81 \mathrm{a}$ & $19 \mathrm{~b}$ \\
\hline \multicolumn{8}{|c|}{ Médias: fonte de potássio } \\
\hline \multicolumn{3}{|c|}{ Vinhaça $^{(4)}$} & $31 \mathrm{a}$ & $11 \mathrm{a}$ & $27 \mathrm{a}$ & $64 \mathrm{a}$ & $36 \mathrm{a}$ \\
\hline \multicolumn{3}{|l|}{$\mathrm{KCl}^{(4)^{3}}$} & $32 \mathrm{a}$ & $10 \mathrm{a}$ & $29 \mathrm{a}$ & $67 \mathrm{a}$ & $33 \mathrm{a}$ \\
\hline & & & Valor de & & \\
\hline & \multicolumn{2}{|c|}{ Cobertura do solo $(\mathrm{C})$} & $1,3^{\mathrm{ns}}$ & - & $73^{*}$ & $0,4^{\mathrm{ns}}$ & $0,4^{\mathrm{ns}}$ \\
\hline \multicolumn{3}{|c|}{ Localização da uréia (L) } & $31,5^{*}$ & $6,7 *$ & $292 *$ & $185^{*}$ & $186^{*}$ \\
\hline \multicolumn{3}{|c|}{ Fonte de potássio $(\mathrm{F})$} & $0,5^{\mathrm{ns}}$ & $0,1^{\mathrm{ns}}$ & $1,8^{\mathrm{ns}}$ & $1,5^{\mathrm{ns}}$ & $1,4^{\mathrm{ns}}$ \\
\hline \multicolumn{3}{|c|}{$\mathrm{C} \times \mathrm{L}$} & $1,0^{\mathrm{ns}}$ & - & $10,7 *$ & $2,5^{\mathrm{ns}}$ & $2,5^{\mathrm{ns}}$ \\
\hline \multicolumn{3}{|l|}{$\mathrm{C} \times \mathrm{F}$} & $0,05^{\mathrm{ns}}$ & - & $6,0^{*}$ & $1,9^{\mathrm{ns}}$ & $1,9^{\mathrm{ns}}$ \\
\hline \multicolumn{3}{|l|}{$\mathrm{L} x \mathrm{~F}$} & $0,4^{\mathrm{ns}}$ & $1,3^{\mathrm{ns}}$ & $8,2 *$ & $2,9^{\mathrm{ns}}$ & $2,9^{\mathrm{ns}}$ \\
\hline \multicolumn{3}{|l|}{$\mathrm{C} \times \mathrm{L} \times \mathrm{F}$} & $0,08^{\mathrm{ns}}$ & - & $1,6^{\mathrm{ns}}$ & $2,2^{\mathrm{ns}}$ & $2,2^{\mathrm{ns}}$ \\
\hline \multicolumn{3}{|l|}{$\mathrm{CV}(\%)$} & 15 & 34 & 12 & 9 & 16 \\
\hline
\end{tabular}

${ }^{(1)}$ Solo-planta representa o somatório das recuperações do $\mathrm{N}$ da uréia no sistema solo-palha-planta. ${ }^{(2)}$ Perdas $=100$ - (solo-planta). ${ }^{\left({ }^{3}\right)}$ Média e desvio-

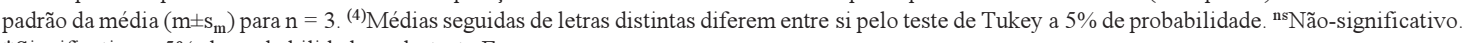
*Significativo a $5 \%$ de probabilidade, pelo teste $\mathrm{F}$. 
Os resultados do desmembramento das interações significativas da análise de variância indicaram de forma geral, independentemente da fonte de $\mathrm{K}$, que as maiores recuperações na planta ocorreram sem a cobertura de palha e com a uréia aplicada em profundidade no solo (Tabelas 2 e 3 ). Esses resultados evidenciaram que a aplicação da uréia em superfície e em solo coberto com palha, resultaram nas menores recuperações do N-fertilizante na cana-soca, decorrentes, em grande parte, de perdas do N-uréia por volatilização de amônia, no solo.

Somente o fator localização do fertilizante mostrou efeito na recuperação do N-uréia no sistema soloplanta (Tabela 2). Sua aplicação em profundidade no solo resultou em $81 \%$ de recuperação, enquanto a superficial, somente em 50\%. A cobertura do solo, simulando as condições com e sem queima do canavial (CQ e SQ), e a fonte de K não mostraram efeito na recuperação do $\mathrm{N}$ da uréia no sistema solo-planta. Esses resultados indicam que no manejo de canaviais sem ou com queima - com ou sem palha cobrindo a superfície do solo - a aplicação da uréia deve, preferencialmente, ser feita em profundidade.

Considerando-se que neste experimento, também não se constatou a lixiviação do $\mathrm{N}$-fertilizante (Oliveira, 1999), as perdas do sistema solo-planta, no tratamento com fertilizante aplicado em profundidade, representaram as perdas para a atmosfera (Tabela 2). As perdas de $50 \%$ do N-uréia aplicado em superfície representam aquelas que ocorreram no solo, principalmente, por volatilização de amônia, e pela parte aérea da cultura.

No experimento com cana-soca, nas condições de solo coberto, ou não, com palha, não deve ter

Tabela 3. Recuperação porcentual do nitrogênio da uréia na planta no ciclo de cana-soca ${ }^{(1)}$

\begin{tabular}{lccccc}
\hline Localização da uréia & \multicolumn{2}{c}{ Cobertura do solo } & & \multicolumn{2}{c}{ Fonte de potássio } \\
\cline { 2 - 3 } \cline { 6 - 6 } & Com palha & Sem palha & & Vinhaça & $\mathrm{KCl}$ \\
\hline Profundidade & $36 \mathrm{aB}$ & $43 \mathrm{aA}$ & & $41 \mathrm{aA}$ & $39 \mathrm{aA}$ \\
Superfície & $9 \mathrm{bB}$ & $25 \mathrm{bA}$ & & $14 \mathrm{bB}$ & $19 \mathrm{bA}$ \\
\hline Fonte de potássio & & & & \\
Vinhaça & $23 \mathrm{aB}$ & $31 \mathrm{bA}$ & & \\
$\mathrm{KCl}$ & $22 \mathrm{aB}$ & $37 \mathrm{aA}$ & & \\
\hline
\end{tabular}

(1)Desdobramento das interações significativas da análise de variância médias seguidas da mesma letra, minúscula na coluna e maiúscula na linha não diferem estatisticamente entre si pelo teste de Tukey a $5 \%$ de probabilidade. ocorrido a estimulação de atividade microbiana, pelo menos com a intensidade que se supôs no experimento com cana-planta e, conseqüentemente, não deve ter havido consumo excessivo de oxigênio do ar do solo, caracterizando condições extremas de anaerobiose que justificassem a desnitrificação. Durante a realização deste experimento, ao contrário do primeiro, a pluviosidade foi baixa $(923 \mathrm{~mm})$ o que exigiu a aplicação de $916 \mathrm{~mm}$ de água, ficando reduzida a possibilidade da desnitrificação. Assim, pode-se afirmar que, nos tratamentos com uréia aplicada em superfície, as perdas deveram-se à volatilização de amônia do solo e da folhagem. Nos tratamentos com aplicação da uréia em profundidade, o resultado médio de $19 \%$ representa as perdas pela parte aérea das plantas, uma vez que é desprezível a volatilização de amônia do solo (Tabela 2).

Os resultados de perdas do N-fertilizante do sistema solo-planta, nos dois experimentos, parecem indicar que o ponto de compensação para absorção/ emissão de amônia na cana-de-açúcar não foi o mesmo nos ciclos de cana-planta e cana-soca. Na canaplanta, o índice pode ter sido inferior à concentração de $\mathrm{NH}_{3}$ da atmosfera, prevalecendo a absorção, enquanto, na rebrota, o ponto de compensação para amônia foi superior à concentração de amônia do ar, pelo menos no período compreendido entre a metade e o fim do ciclo da cultura, quando ocorrem as perdas, como constatado indiretamente por $\mathrm{Ng} \mathrm{Kee}$ Kwong \& Deville (1994a, 1994b) e Trivelin et al. (1996). Uma possível explicação para esses resultados pode estar no regime hídrico (Figura 1), associado aos fatores meteorológicos como temperatura do ar, radiação solar e velocidade do vento, que levou a cana-soca a apresentar maior perda de $\mathrm{N}$ pela parte aérea, com aumento no ponto de compensação de amônia. Plantas em condições de deficiência hídrica aceleram a degradação de proteínas, diminuindo a síntese (Hasiao, 1973; Du et al., 1996), que, por conseqüência, pode levar a perdas de $\mathrm{N}$ pela parte aérea.

Supondo-se que no caso de as perdas do N-uréia em cana-soca, com o fertilizante aplicado em profundidade, terem ocorrido unicamente por volatilização de $\mathrm{NH}_{3}$ da parte aérea, e considerado, ao final do ciclo, um acúmulo de $\mathrm{N}$ na parte aérea da cultura de aproximadamente $200 \mathrm{~kg} \mathrm{ha}^{-1}$, sendo $20 \%$ desse N, 
como valor médio (Trivelin et al., 1995, 1996), derivado da uréia, as perdas totais $(\mathrm{N}$ derivado da uréia $\mathrm{e}$ de outras fontes assimilado pela cana-de-açúcar) foram da ordem de $90 \mathrm{~kg} \mathrm{ha}^{-1} \mathrm{de} \mathrm{N}$.

\section{Conclusões}

1. As perdas do N-uréia no sistema solo-planta no ciclo de cana-soca são superiores às de cana-planta.

2. No ciclo de cana-soca, as maiores perdas do $\mathrm{N}$-uréia no sistema solo-planta ocorrem quando o fertilizante é aplicado na superfície.

3. As perdas de $\mathrm{N}$ pela folhagem da cana-de-açúcar, no ciclo de cana-soca, são da ordem de $90 \mathrm{~kg} \mathrm{ha}^{-1}$ de N.

\section{Agradecimentos}

À Usina Costa Pinto S.A. Açúcar e Álcool e ao Centro de Tecnologia da Copersucar, Divisão de Agronomia e Engenharia Agrícola, pelo apoio na execução deste estudo; à Fapesp e CNPq, pelo financiamento da pesquisa.

\section{Referências}

ABRAMO FILHO, J.; MATSUOKA, S.; SPERANDIO, M. L.; RODRIGUES, R. C. D.; MARCHETTI, L. L. Resíduo da colheita mecanizada de cana crua. Álcool \& Açúcar, São Paulo, n. 67, p. 23-25, abr./maio 1993.

BOUWMAN, A. F.; LEE, D. S.; WAH, A.; DENTENER, F. .J.; VANDERHOEK, K. W.; OLIVIER, J. G. J.A global high-resolution emission inventory for ammonia. Global Biogeochemical Cycles, Washington, v. 11, n. 4, p. 561$587,1997$.

CAMARGO, P. B. Dinâmica do nitrogênio dos fertilizantes uréia $\left({ }^{15} \mathrm{~N}\right)$ e aquamônia $\left({ }^{15} \mathrm{~N}\right)$ incorporados ao solo na cultura de cana-de-açúcar. Piracicaba: Esalq, 1989. 104 p. Dissertação de Mestrado.

DOBBIE, K. E.; MctAGgART, I. P.; SMITH, K. A Nitrous oxide emissions from intensive agricultural systems: variations between crops and seasons, key driving variables, and mean emission factors. Journal of Geophysical Research Atmosphere, Washington, v. 104, n. D21, p. 26891-26899, 1999.
DU, Y. C.; KAWAMITSU, Y.; NOSE, A.; HIYANE, S.; MURAYAMA, S.; WASANO, K.; UCHIDA, Y. Effects of water stress on carbon exchange rate and activities of photosynthetic enzymes in leaves of sugarcane (Saccharum sp.). Australian Journal of Plant Physiology, Collingwood, v. 23, n. 6, p. 719-726, 1996.

DUXBURY, J. M. The significance of agricultural sources of greenhouse gases. Fertilizer Research, Dordrecht, v. 38, n. 1, p. $151-163,1994$.

FARQUHAR, G. D.; FIRTH, P. M.; WETSELAAR, R.; WEIR, B. On the gaseous exchange of ammonia between leaves and the environment: determination of the ammonia compensation point. Plant Physiology, Rockville, v. 66, p. $710-714,1980$.

GAVA, G. J. C. Utilização do nitrogênio da uréia $\left({ }^{15} \mathbf{N}\right)$ e da palhada $\left({ }^{15} \mathrm{~N}\right)$ por soqueira de cana-de-açúcar no manejo sem despalha a fogo. Piracicaba: USP, 1999. 81 p. Dissertação de Mestrado.

HASIAO, T. C. Plant response to water stress. Annual Review of Plant Physiology, Palo Alto, v. 24, p. 519570,1973

HOLTAN-HARTWIG, L.; BOCKMAN, O. C. Ammonia exchange between crops and air. Norwegian Journal of Agricultural Sciences, Aas, v. 14, p. 1-41, 1994 Supplement.

HUSTED, S.; MATTSSON, M.; SCHJOERRING, J. K. Ammonia compensation points in two cultivars of Hordeum vulgare $\mathrm{L}$. during vegetative and generative growth. Plant Cell and Environment, Oxford, v. 19, n. 11, p. 1299-1306, 1996.

KEENEY, D. R.; NELSON, D. W. Nitrogen: inorganic forms. In: PAGE, A. L.; MILLER, R. H.; KEENEY, D. R. (Ed.). Methods of soil analysis. 2. ed. Madison: American Society of Agronomy, 1982. p. 643-689. (Agronomy, 9).

LARA CABEZAS, W. A. R.; TRIVELIN, P. C. O.; VICTORIA, R. L.; CAMARGO, P. B.; PICCOLO, M. C. Volatilização de amônia da uréia- ${ }^{15} \mathrm{~N}$ e aquamônia- ${ }^{15} \mathrm{~N}$ aplicadas na cultura da cana-de-açúcar em condições de campo. In: CONGRESSO NACIONAL DA SOCIEDADE DOS TÉCNICOS AÇUCAREIROS E ALCOOLEIROS DO BRASIL, 4.; CONVENÇÃO DAACTALAC, 7., 1987, Olinda, Anais... Olinda: Stab, 1987. p. 50-59.

LOBERT, J. M.; SCHSRFFE, D. H.; HAO, W. M.; CRUTZEN, P. J. Importance of biomass burning in the atmospheric budgets of nitrogen-containing gases. Nature, London, v. 346, p. 552-554, 1990. 
MATTSSON, M.; HAUSLER, R. E.; LEEGOOD, R. C.; SCHJOERRING, J. K. Leaf-atmosphere $\mathrm{NH}_{3}$ exchange in barley mutants with reduced activities of glutamine synthetase. Plant Physiology, Rockville, v. 114, n. 4, p. $1307-1312,1997$

MATTSSON, M.; SCHJOERRING, J. K. Characteristics of ammonia emission from barley plants. Plant Physiology and Biochemistry, Paris, v. 34, n. 5, p. 691-695, 1996.

NG KEE KWONG, K. F.; DEVILLE, J. Application of ${ }^{15} \mathrm{~N}$-labeled urea to sugar cane through a drip-irrigation system in Mauritius. Fertilizer Research, Dordrecht, v. 39 , p. $223-228,1994 a$.

NG KEE KWONG, K. F; DEVILLE, J. The course of fertilizer nitrogen uptake by rain fed sugarcane in Mauritius. Journal of Agricultural Sciences, Cambridge, Inglaterra, v. 122 , p. $385-391,1994 b$

OLIVEIRA, M. W. Dinâmica do nitrogênio da uréia $\left({ }^{15} \mathrm{~N}\right)$ no sistema solo-cana-de-açúcar com ou sem queima da palhada. Piracicaba: USP, 1999. 93 p. Tese de Doutorado

OLIVEIRA, M. W.; TRIVELIN, P. C. O.; GAVA, G. J. C.; VITTI, A. C. Lixiviação de nitrogênio em solo cultivado com cana-de-açúcar: experimento em lisímetro. STAB Açúcar, Álcool e Subprodutos, Piracicaba, v. 18, n. 2, p. 28-31, 1999.

QUARTA geração de variedades de cana-de-açúcar. Boletim Técnico Copersucar, Piracicaba, dez. 1993. 16 p. Edição Especial.

SCHJOERRING, J. K.; HUSTED, S.; MATTSSON, M Physiological parameters controlling plant-atmosphere ammonia exchange. Atmospheric Environment, Oxford, v. 32, n. 3, p. 491-498, 1998.

SCHLESINGER, W. H.; HARTLEY,A. E. A global budget for atmospheric $\mathrm{NH}_{3}$. Biogeochemistry, Dordrecht, v. 15 , p. $191-211,1992$
SILVA, L. C. F.; CASAGRANDE, J. C. Nutrição mineral da cana-de-açúcar (macronutrientes). In: ORLANDO FILHO, J. (Coord.). Nutrição e adubação da cana-de-açúcar no Brasil. Piracicaba: IAA/Planalsucar, 1983. p. $77-99$

TRIVELIN, P. C. O. Utilização do nitrogênio pela canade-açúcar: três casos estudados com uso do traçador ${ }^{15} \mathbf{N}$. Piracicaba: USP, 2000. 143 p. Tese de Livre-Docência.

TRIVELIN, P. C. O.; LARA CABEZAS, W. A. R.; BOARETO,A. E. Dinâmica do nitrogênio de fertilizantes fluidos no sistema solo-planta. In: VITTI, G. C.; BOARETO,A E. (Ed.). Fertilizantes fluidos. Piracicaba: Potafos, 1994. p. 253-268.

TRIVELIN, P. C. O.; RODRIGUES, J. C. S.; VICTORIA, R. L. Utilização por soqueira de cana-de-açúcar de início de safra do nitrogênio da aquamônia- ${ }^{15} \mathrm{~N}$ e uréia- ${ }^{15} \mathrm{~N}$ aplicado ao solo em complemento à vinhaça. Pesquisa Agropecuária Brasileira, Brasília, v. 31, n. 2, p. 89-99, fev. 1996

TRIVELIN, P. C. O.; SALATI, E.; MATSUI, E. Preparo de amostras para análise de ${ }^{15} \mathrm{~N}$ por espectrometria de massa. Piracicaba: USP-Cena, 1973. 41 p. (Boletim Técnico).

TRIVELIN, P. C. O.; VICTORIA, R. L.; RODRIGUES, J. C. S. Aproveitamento por soqueira de cana-de-açúcar de final de safra do nitrogênio da aquamônia- ${ }^{15} \mathrm{~N}$ e uréia ${ }^{15} \mathrm{~N}$ aplicado ao solo em complemento à vinhaça. Pesquisa Agropecuária Brasileira, Brasília, v. 30, n. 12, p. 1375 1385, dez. 1995

WEIER, K. L. Sugarcane fields: sources or sinks for greenhouse gas emissions? Australian Journal of Agricultural Research, Collingwood, v. 49, p. 1-9, 1998. 